\title{
Drinking water supplementation of licorice (Glycyrrhiza glabra L. root) extract as an alternative to in-feed antibiotic growth promoter in broiler chickens
}

\author{
Moradi Naser ${ }^{1}$, Ghazi Shahab ${ }^{1}$ and Habibian Mahmood 2,* \\ ${ }^{1}$ Department of Animal Science, College of Agriculture and Natural Resources, Razi University, Kermanshah, Iran \\ 2 Department of Animal Science, Faculty of Agriculture, University of Kurdistan, Sanandaj, Iran
}

Publication history: Received on 29 September 2017; revised on 08 November 2017; accepted on 15 November 2017

https://doi.org/10.30574/gscbps.2017.1.3.0039

\begin{abstract}
The present study was conducted to determine the efficacy of licorice extract (LE) supplementation through drinking water as an alternative to an in-feed antibiotic growth promoter. A total of 4001 -day-old broiler chickens (Cobb 500) were randomly divided into 20 separate floor pens each comprising 20 chickens and 4 pens (replicates) per treatment in a completely randomized design. The treatments included a control (no input), a diet containing $5 \mathrm{mg} / \mathrm{kg}$ antibiotic (lincomycin), and drinking water supplemented with $0.1,0.2$, or $0.3 \mathrm{~g} / \mathrm{L}$ of LE, respectively. The body weight, feed intake, and feed conversion ratio were not significantly different among treatment groups $(P>0.05)$. Birds given drink water supplemented with $0.3 \mathrm{~g} / \mathrm{L}$ of LE had significantly decreased abdominal fat percentage relative to control group $(P<$ 0.05). Moreover, comparing with control, serum concentrations of glucose, low-density lipoprotein cholesterol and total cholesterol were decreased by LE supplementation at all three tested levels $(P<0.05)$. Dietary supplemental of antibiotics also caused significant decreases in total cholesterol and low-density lipoprotein cholesterol concentrations $(P<0.05)$. These results clearly showed that LE supplementation via drinking water had beneficial and positive influences on carcass quality and blood biochemical parameters of broiler chickens. However, because no significant difference was observed on growth performance among the broilers given the control, antibiotic, or the LE levels, further research is still needed to confirm the present results and to test the efficacy of LE as an alternative to an in-feed antibiotic growth promoter.
\end{abstract}

Keywords: Performance; carcass trait; blood biochemical parameters; licorice extract; antibiotic

\section{Introduction}

In-feed antibiotics have been used in the poultry industry to maintain health and production efficiency in the last few decades. However, antibiotics have been banned to prevent the development of antibiotics-resistant pathogenic bacteria and to eliminate antibiotic residues from poultry products [1]. As a consequence, the search for alternatives to replace antibiotics has gained increasing interest in poultry nutrition in recent years.

One replacement candidate is licorice, the root of the leguminous Glycyrrhiza plant species, Glycyrrhiza glabra L. It has been reported that licorice has antimicrobial, anti-Helicobacter, antiatherosclerotic, antioxidative, antiinflammatory, antifungal, estrogen-like, antiviral, anti-infective, antinephritic, and radical scavenging activities [2]. According to phytochemical analysis, the major fraction of licorice extract (LE) consists of triterpene saponins (e.g., glycyrrhizin, glycyrrhetinic acid, and licorice acid) and flavonoids (e.g., liquiritin, isoflavonoids, and formononetin), sugars, starch, amino acids, ascorbic acid, tannins, choline, coumarins, phytosterols, and some other bitter principles [3]. Importantly, numerous pharmacological effects have been described for LE and its isolated active principles in mice and rats.

\footnotetext{
${ }^{*}$ Corresponding author

E-mail address: mahmood_habibiyan@yahoo.com
}

Copyright (C) 2017 Author(s) retain the copyright of this article. This article is published under the terms of the Creative Commons Attribution Liscense 4.0. 
Therefore, the extract are used as a remedy for the treatment of different ailments and disorders such as hypocortisolism [4], bronchitis, cough, arthritis, rheumatism, hypoglycemia [5], inflammatory and allergic conditions [6], gastric ulcer [7], and chronic hepatitis B and C [8].

Tominaga et al. [9] proposed that licorice flavonoid oil (LFO) is a lipotropic agent that can be administered orally to human subjects over a long period of time in order to improve body composition and reduce the occurrence of obesity. Aoki et al. [10] also showed an increase in lean body mass and a decrease in abdominal fat pad as a physiological effect of LFO that stimulates lipid breakdown in adipocytes. These findings have been confirmed in successive studies [11, 12].

Despite such beneficial effects, the impacts of LE on body weight gain of broilers in association to different blood parameters are not fully known. Therefore, the current study presents a trial using LE supplementation in drinking water, as a potential antimicrobial agent, to improve production performance, carcass quality, and blood parameters in broiler chickens.

\section{Material and methods}

\subsection{Birds and experimental treatments}

A total of 400 1-day-old broiler chickens (Cobb 500) were purchased from a commercial broiler hatchery (Baharan Company, Kermanshah, Iran) and were used in this study. The broilers were housed in identical-sized floor pens (20 pens; 10 males and 10 females per pen; $0.21 \mathrm{~m}^{2} / \mathrm{bird}$ ). Each pen was covered with a 5-cm layer of straw and fitted with one bell drinker and one hanging tube feeder. Temperature was set at $33{ }^{\circ} \mathrm{C}$ on day 1 and gradually reduced by $1{ }^{\circ} \mathrm{C}$ every 2 days until $21^{\circ} \mathrm{C}$ was reached. Relative humidity was not controlled during the study. A continuous light regimen was used during the first week of rearing period, and then $23 \mathrm{~h}$ lighting was applied up to 42 days of age.

Table 1 Ingredients and nutrient level of basal diets

\begin{tabular}{lcc}
\hline Item (\%, unless otherwise noted) & Starter (1-21 days) & Finisher (21-42 days) \\
\hline Ingredients & & \\
Corn & 58.91 & 69.94 \\
Soybean meal (48\% crude protein) & 35.82 & 24.19 \\
Soybean oil & 1.59 & 0.50 \\
Oyster shell & 1.32 & \\
Dicalcium phosphate & 1.47 & 1.57 \\
Salt & 0.29 & 0.40 \\
Mineral-vitamin premix ${ }^{1}$ & 0.50 & 0.50 \\
DL-methionine & 0.10 & 0.15 \\
Nutrients composition & & \\
Metabolizable energy (kcal/kg) & 2,919 & 3,000 \\
Crude protein & 21.00 & 18.75 \\
Calcium & 0.91 & 0.84 \\
Available phosphorus & 0.41 & 0.33 \\
Methionine + cysteine & 0.82 & 0.67 \\
Lysine & 1.28 & 1.09 \\
\hline
\end{tabular}

${ }^{1}$ Mineral-vitamin premix provided the following per kilogram of diet: vitamin A, 9,000 IU; vitamin $\mathrm{D}_{3}, 2,100$ IU; vitamin E, 30 mg; nicotinic acid, 30 mg; vitamin $\mathrm{B}_{12}, 0.12 \mathrm{mg}$; calcium pantothenate, $10 \mathrm{mg}$; vitamin $\mathrm{K}_{3}, 5 \mathrm{mg}$; thiamine, $1.1 \mathrm{mg}$; riboflavin, $4.5 \mathrm{mg}$; vitamin $\mathrm{B}_{6}, 2.0 \mathrm{mg}$; folic acid, $0.5 \mathrm{mg}$; biotin, $0.5 \mathrm{mg}$; Fe, $50 \mathrm{mg}$; Cu, $10 \mathrm{mg}$; Mn, $70 \mathrm{mg}$; Zn, $50 \mathrm{mg}$; I, $1.0 \mathrm{mg}$; Se, $0.3 \mathrm{mg}$; butylated hydroxytoluene,150 mg.

The birds were randomly divided into 5 groups. Each group had 4 replicates. Group 1 consisted of broilers that received a basal diet and tap water and served as the control. Group 2 had broilers which received a basal diet supplemented with $5 \mathrm{mg} / \mathrm{kg}$ of lincomycin (Lincodan 8.8, Roshd daneh, Gorgan, Iran) and tap water. Group 3 was composed of broilers that received a basal diet and water supplemented with $0.1 \mathrm{~g} / \mathrm{L}$ of LE. Group 4 had broilers which received a basal diet and water supplemented with $0.2 \mathrm{~g} / \mathrm{L}$ of LE. Finally, group 5 was composed of broilers that received a basal diet and water supplemented with $0.3 \mathrm{~g} / \mathrm{L}$ of LE. The LE was obtained from a commercial company (Zagros Company, Kermanshah, Iran). Broilers were provided ad libitum access to feed and water according to a 2-phase feeding program on a starter and a finisher diet during the periods of 1 to 21 days and 21 to 42 days of age, respectively. The basal diets with ingredient composition are shown in Table 1. 


\subsection{Growth performance}

Data on feed intake and body weight were recorded on 1,21, and 42 days of age. Mortality was recorded as it occurred and feed intake adjusted accordingly.

\subsection{Determination of blood biochemical parameters and organ weights}

At the end of the experiment (day 42), after an overnight starvation, 8 chickens from each treatment were selected randomly, weighed, and bled by wing vein puncture. The blood samples were collected in non-heparinized collection tubes. Serum was obtained by centrifuging collected blood samples for 20 min at 3,000 rpm $\left(1600 \times \mathrm{g}\right.$, $\left.4{ }^{\circ} \mathrm{C}\right)$ and was stored and frozen at $-20{ }^{\circ} \mathrm{C}$ until further analysis. Thereafter, chickens were slaughtered and their organs were weighted. Carcass yield was calculated as a percentage, i.e., eviscerated carcass weight without neck, giblets, and abdominal and gizzard fats divided by live body weight before evisceration. The weights of breast, thigh, liver, gall bladder, pancreas, and abdominal fat were also recorded and expressed as percentage of the live body weight. Serum concentrations of glucose, triacylglycerols, high-density lipoprotein (HDL) cholesterol, low-density lipoprotein (LDL) cholesterol, and total cholesterol were analyzed using commercially available enzymatic spectrophotometric kits (Pars Azmun Kits, Pars Azmun Inc., Tehran, Iran). All samples were analyzed in triplicate in a single assay to minimize interassay variance.

\subsection{Statistical analysis}

The data were analyzed using the GLM procedure of SAS software [13] as a completely randomized design. The mean values were compared by Duncan's multiple-range tests at $P<0.05$. The experimental unit differed according to the parameter that was measured. For performance characteristics, the experimental unit was pen, whereas individual chick data were used for serum biochemical parameters.

\section{Results}

\subsection{Growth performance}

As shown in Table 2, body weight, weight gain, feed intake, and feed conversion ratio of broiler chickens were not significantly different among treatment groups $(P>0.05)$.

Table 2 Effects of treatments on body weight, weight gain, feed intake, and feed conversion ratio of broilers

\begin{tabular}{|c|c|c|c|c|c|c|c|}
\hline \multirow{2}{*}{ Items } & \multirow[b]{2}{*}{ Control } & \multirow[b]{2}{*}{ Antibiotic 1} & \multicolumn{3}{|c|}{ Licorice extract (g/L) } & \multirow[t]{2}{*}{ SEM $^{2}$} & \multirow[t]{2}{*}{$P$ values } \\
\hline & & & 0.1 & 0.2 & 0.3 & & \\
\hline \multicolumn{8}{|c|}{ Body weight (g) } \\
\hline Day 21 & 851 & 857 & 858 & 863 & 845 & 5.3 & 0.882 \\
\hline Day 42 & 2,668 & 2,652 & 2,605 & 2,630 & 2,612 & 22.4 & 0.911 \\
\hline \multicolumn{8}{|c|}{ Weight gain (g/bird/day) } \\
\hline Days 1-21 & 38.5 & 38.9 & 38.9 & 39.0 & 38.3 & 0.25 & 0.901 \\
\hline Days 21-42 & 86.5 & 85.5 & 83.2 & 84.1 & 84.1 & 0.89 & 0.821 \\
\hline Days 1-42 & 62.5 & 62.2 & 61.0 & 61.6 & 61.2 & 0.53 & 0.913 \\
\hline \multicolumn{8}{|c|}{ Feed intake (g/bird/day) } \\
\hline Days 1-21 & 70.9 & 72.0 & 72.0 & 71.7 & 70.3 & 0.26 & 0.238 \\
\hline Days 21-42 & 160.3 & 161.1 & 160.6 & 160.4 & 163.2 & 0.50 & 0.331 \\
\hline Days 1-42 & 115.6 & 116.3 & 116.3 & 116.1 & 116.8 & 0.22 & 0.595 \\
\hline \multicolumn{8}{|c|}{ Feed conversion ratio (g/g) } \\
\hline Days 1-21 & 1.84 & 1.84 & 1.85 & 1.83 & 1.83 & 0.013 & 0.992 \\
\hline Days 21-42 & 1.85 & 1.88 & 1.93 & 1.90 & 1.94 & 0.019 & 0.580 \\
\hline Days 1-42 & 1.85 & 1.86 & 1.89 & 1.87 & 1.89 & 0.011 & 0.850 \\
\hline
\end{tabular}




\subsection{Carcass traits}

The effects of treatments on carcass traits of broiler chickens are shown in Table 3. Carcass, breast, and thigh yields were not affected by treatments $(P>0.05)$. Similarly, no obvious effect of treatments was found in terms of liver and pancreas weights $(P>0.05)$; although, the mean pancreas weight tended to decrease due to dietary antibiotic supplementation. The abdominal fat percentage tended to decrease as the levels of LE in the drinking water were increased, and it was significantly reduced when broilers were given water containing $0.3 \mathrm{~g} / \mathrm{L}$ of $\mathrm{LE}(P<0.05)$.

Table 3 Effects of treatments on carcass traits of 42-days-old broilers

\begin{tabular}{|c|c|c|c|c|c|c|c|}
\hline \multirow{2}{*}{ Items } & \multirow[b]{2}{*}{ Control } & \multirow[b]{2}{*}{ Antibiotic ${ }^{1}$} & \multicolumn{3}{|c|}{ Licorice extract (g/L) } & \multirow[t]{2}{*}{ SEM $^{2}$} & \multirow[t]{2}{*}{$P$ values } \\
\hline & & & 0.1 & 0.2 & 0.3 & & \\
\hline Carcass yield & 71.08 & 72.05 & 72.92 & 74.97 & 73.59 & 0.622 & 0.115 \\
\hline Breast yield & 30.85 & 31.34 & 32.62 & 33.60 & 31.72 & 0.433 & 0.291 \\
\hline Thigh yield & 19.51 & 20.29 & 21.38 & 20.68 & 20.90 & 0.24 & 0.128 \\
\hline Liver & 1.79 & 1.74 & 1.77 & 1.59 & 1.85 & 0.037 & 0.265 \\
\hline Gall bladder & $0.14^{\mathrm{a}}$ & $0.08^{b}$ & $0.08^{\mathrm{b}}$ & $0.12^{\mathrm{ab}}$ & $0.10^{\mathrm{ab}}$ & 0.007 & 0.022 \\
\hline Pancreas & 0.19 & 0.13 & 0.16 & 0.16 & 0.18 & 0.007 & 0.095 \\
\hline Abdominal fat & $2.33^{\mathrm{a}}$ & $2.35^{\mathrm{a}}$ & $1.65^{\mathrm{ab}}$ & $1.54^{\mathrm{ab}}$ & $1.38^{\mathrm{b}}$ & 0.136 & 0.04 \\
\hline
\end{tabular}

a-c Means within a column showing different lowercase letters are significantly different $(P<0.05)$; Duncan's multiple-range tests were applied to compare means; ${ }^{1}$ Antibiotic $=5 \mathrm{mg}$ of lincomycin/kg of diet (Lincodan 8.8, Roshd daneh, Gorgan, Iran); and ${ }^{2}$ Standard error of mean that applies to the statistical model.

\subsection{Blood biochemical parameters}

The effects of treatments on blood biochemical indices of 42-days-old broilers are given in Table 4 . The serum concentration of glucose decreased in broilers that received in-feed antibiotics and those given 0.2 and $0.3 \mathrm{~g} / \mathrm{L}$ of LE through drinking water $(P<0.05)$, whereas serum triacylglycerols and HDL cholesterol concentrations were not significantly affected by treatments $(P>0.05)$. In addition, the serum total cholesterol and LDL cholesterol concentrations decreased in chickens fed a dietary antibiotic or given LE through drinking water $(P<0.05)$; with broilers receiving $0.3 \mathrm{~g} / \mathrm{L}$ of LE showed the lowest concentrations of total and LDL cholesterol. Broilers in the latter group also had a significantly higher HDL-to-LDL ratio compared with other treatment groups $(P<0.05)$.

Table 4 Effects of treatments on blood parameters (mmol/L) of 42-days-old broilers

\begin{tabular}{|c|c|c|c|c|c|c|c|}
\hline \multirow{2}{*}{ Items } & \multirow[b]{2}{*}{ Control } & \multirow[b]{2}{*}{ Antibiotic $^{1}$} & \multicolumn{3}{|c|}{ Licorice extract (g/L) } & \multirow[t]{2}{*}{ SEM $^{2}$} & \multirow[t]{2}{*}{$P$ values } \\
\hline & & & 0.1 & 0.2 & 0.3 & & \\
\hline Glucose & $13.74^{\mathrm{a}}$ & $10.63^{\mathrm{bc}}$ & $11.95^{b}$ & $10.05^{c}$ & $9.28^{c}$ & 0.422 & 0.0004 \\
\hline Triacylglycerols & 0.85 & 0.93 & 1.07 & 0.88 & 0.75 & 0.068 & 0.741 \\
\hline HDL-cholesterol $^{3}$ & 1.52 & 1.72 & 1.78 & 2.03 & 1.97 & 0.072 & 0.144 \\
\hline LDL-cholesterol $^{4}$ & $0.85^{\mathrm{a}}$ & $0.58^{\mathrm{b}}$ & $0.56^{\mathrm{b}}$ & $0.43^{\mathrm{bc}}$ & $0.25^{c}$ & 0.053 & 0.0003 \\
\hline HDL to LDL ratio & $1.80^{\mathrm{b}}$ & $3.36^{\mathrm{b}}$ & $3.33^{\mathrm{b}}$ & $4.70^{\mathrm{b}}$ & $9.35^{\mathrm{a}}$ & 0.767 & 0.006 \\
\hline Total cholesterol & $4.07^{\mathrm{a}}$ & $3.11^{\mathrm{b}}$ & $3.03^{\mathrm{bc}}$ & $2.84 \mathrm{bc}$ & $2.56^{c}$ & 0.133 & 0.0001 \\
\hline
\end{tabular}

\section{Discussion}

In the current study, productive performance of broilers were not significantly affected by LE supplementation of water or antibiotic supplementation of diet. These results are comparable with those reported by other researchers $[14,15]$, who studied the effect of dietary supplementation of LE on broiler chickens $(0.5,1.0$, and $2.0 \mathrm{~g} / \mathrm{kg}$ of diet) or Japanese quails $(0.2 \mathrm{~g} / \mathrm{kg}$ of diet). Conversely, Al-Daraji [16] evinced a highly significant increase in mean body weight at 4 to 8 
weeks of age in heat-stressed broiler chickens receiving LE in their drinking water $(0.45 \mathrm{~g} / \mathrm{L}$ of water) as compared with control birds or birds receiving probiotic treatment. Growth performance was also shown to be improved with other herbal product supplementation through drinking water in heat-stressed broiler chickens. The examples include Pluchea indica L. extract at $0.1,0.2,0.4$, and $0.8 \mathrm{~g} / \mathrm{L}$ of water [17] and Eugenia caryophyllus Spreng. extract or essential oil at $0.4 \mathrm{~g} / \mathrm{L}$ of water [18]. As the feed intake and feed conversion efficiency can affect by heat stress [19], the results of the present study are not comparable with those of the previously mentioned studies. Moreover, the effects of different medicinal plants are often not directly able to be compared because of the naturally varying composition of extracts and essential oils, even in the same plant species, due to the presence of chemiotypes, different harvest times, different extraction methods and etc.

Contradictory reports exist concerning the effects of in-feed antibiotics on the growth performance of broilers under normal rearing conditions. Eseceli et al. [20] reported no difference in gain or feed intake of broilers fed avilamycin (1 $\mathrm{g} / \mathrm{kg}$ of diet), whereas Sarker et al. [21] reported no differences in body weight or feed conversion ratio when broilers were fed diets containing $50 \mathrm{mg} / \mathrm{kg}$ of oxytetracycline. Lee et al. [22] also reported no difference in gain or feed efficiency of broilers fed diets containing $55 \mathrm{mg} / \mathrm{kg}$ of bacitracin, $2.5 \mathrm{mg} / \mathrm{kg}$ of nosiheptide, or $55 \mathrm{mg} / \mathrm{kg}$ of oxytetracycline. However, the result of other studies using antibiotics indicated improved body weight gain and feed conversion ratio in broiler chickens [23-25]. The lack of agreement among these studies may be partially explained by both the antibiotic source and administration level. Nevertheless, the efficacy of an antibiotic agent may be influenced by several other factors, such as differences in background of the targeted populations, bird age, overall farm hygiene, and etc. It is important to note that, although in-feed antibiotics improve performance approximately $70 \%$ of the time in production poultry, no favorable effects can be observed in almost one third of the cases [26].

Carcass, breast, and thigh yields were not affected by treatments. Similarly, no obvious effect of treatments was found in terms of liver and pancreas weights. However, the abdominal fat percentage was significantly reduced when broilers were given water containing $0.3 \mathrm{~g} / \mathrm{L}$ of LE. These findings are in agreement with the previously published results [1416]. Sedghi et al. [14] reported a significantly lower abdominal fat percentage in broiler chickens fed different concentrations (0.5, 1.0, and $2.0 \mathrm{~g} / \mathrm{kg}$ of diet) of LE, whereas Pooryousef Myandoab and Hosseini Mansoub [15] reported no differences in carcass yield and liver weight when Japanese quail were fed a diet containing $0.2 \mathrm{~g} / \mathrm{kg}$ of LE. Al-Daraji [16] also reported significantly lower abdominal fat percentage and unchanged carcass yield when heat-stressed broilers received water containing LE ( $0.45 \mathrm{~g} / \mathrm{L}$ of water). Experiments in other species also showed that licorice flavonoids reduced the abdominal fat [9-12].

Suppression of lipid absorption [27], reduction in calorie intake [28], reduction in biosynthesis of fatty acid, and enhancement of fatty acid oxidation [29] are possible mechanisms of the reduction in body fat. In the present study, no significant change in energy intake was observed, as feed intake between treatments did not differ. Changes in lipid absorption were not examined in the present study, but blood triacylglycerols did not change, suggesting that suppression of lipid absorption was probably not a relevant factor. Moreover, Sedghi et al. [14] reported that lipid absorption and serum triacylglycerols concentration were not affected by dietary LE supplementation. Conversely, in the current study, gall bladder weight reduced as a result of drinking water supplementation of LE $(0.1 \mathrm{~g} / \mathrm{L}$ of water $)$. Therefore, LE may have exerted especial effects on lipid digestion and absorption, which could result in reduced energy consumption [30]; further experiments are necessary to confirm this result. Tominaga et al. [9] established a hypothesis that the weight loss by LFO is due to reduction in fatty acid synthesis and enhancement of fatty acid oxidation in the liver, and lines of evidence exist confirming this supposition. For example, Kamisoyama et al. [31] observed that the body weight and white adipose tissue mass of obese mice fed a high-fat diet for 8 weeks were suppressed compared with the control by administration of LFO. A preliminary microarray study using these mice showed that LFO induced genes in some fatty acid oxidation pathways and reduced some fatty acid synthesis pathways in the liver. Further experiments are needed to confirm the mechanism of action. The abdominal fat percentage was not affected by in-feed antibiotics, which is similar to results reported by other researchers [21, 24].

The serum concentration of glucose decreased in broilers that received in-feed antibiotics and those given 0.2 and 0.3 $\mathrm{g} / \mathrm{L}$ of LE through drinking water, whereas serum triacylglycerols and HDL cholesterol concentrations were not significantly affected by treatments. Our serum glucose concentration results agree with those of Nakagawa et al. [12], who found that LFO supplementation $(2 \mathrm{~g} / \mathrm{kg}$ of diet) caused a decrease in the serum concentrations of glucose in experimental diabetic rats after 2 and 4 weeks of administration. Our results also confirm those of Sedghi et al. [14], who reported that dietary LE supplementation did not affect serum concentrations of triacylglycerols and HDL cholesterol in broiler chickens. However, they also found no effect of dietary LE supplementation in the serum levels of glucose. Conversely, Al-Daraji [32] reported that increasing levels of supplemental LE (0.15 to $0.45 \mathrm{~g} / \mathrm{L}$ of water) increased serum glucose concentrations of heat-stressed broiler chickens. At present, the exact mechanism of this difference is still not clear. However, decreasing the level of the serum glucose concentration in the present experiment 
could be further evidence that LE suppresses abdominal fat accumulation via inhibition of fatty acid synthesis pathways. Increased glucose uptake is expected to increase oxidation of glucose, which would otherwise be converted to fatty acids and stored as triacylglycerol in adipose tissues.

Furthermore, in the current study, the serum total cholesterol and LDL cholesterol concentrations decreased in chickens fed a dietary antibiotic or given LE through drinking water; broilers receiving $0.3 \mathrm{~g} / \mathrm{L}$ of LE had significantly lower concentrations of total and LDL cholesterol than those receiving the other treatments. Broilers in the latter group also had a significantly higher HDL-to-LDL ratio compared with other treatment groups. These findings are accorded to other studies [14, 15, 32]. Visavadiya and Narasimhacharya [33] demonstrated that the cholesterol-lowering effects of LE in rats are attributed to an elevated excretion of cholesterol, neutral sterols, bile acid, and an enhancement in hepatic bile acid content. In this regard, the presence of phytosteroids, saponins, and fiber in LE could be important in cholesterol elimination and an increase in hepatic bile acid content in LE-fed animals. It is well known that phytosteroids bind to micelles more easily and tightly in comparison to cholesterol, possibly because of their greater hydrophobicity. As a consequence, these compounds can specifically displace cholesterol from the micelles in the intestinal lumen, thereby reducing intestinal cholesterol absorption and blood cholesterol concentrations [34]. Saponins, however, are reported to have the ability to form insoluble complexes with cholesterol in the digestive tract, and to affect enterohepatic circulation of bile acids, making them inaccessible for intestinal absorption [35]. Dietary fibers also appear to interfere with cholesterol absorption and its enterohepatic bile circulation, which result in a depletion of hepatic cholesterol stores and an enhancement in the rate of clearance of cholesterol from the bloodstream. Besides, the cholesterollowering potential of fiber appears to be mainly because of increased excretion of cholesterol and bile acids [36].

A significant decline in serum LDL cholesterol concentration in these birds could also be correlated with the fiber and saponin content of LE, as both fibers and saponins increase the hepatic LDL receptor levels, enhance the hepatic clearance of LDL cholesterol from circulation, and increase the rate of transformation of cholesterol to bile acids [35, 36]. Whereas dietary saponins and fibers are not known to elevate HDL cholesterol levels [35, 36], ascorbic acid [37] and flavonoids [38] are reported to increase the HDL cholesterol concentrations. The LE contained both ascorbic acid and flavonoids that could have contributed to an increase in the HDL-to-LDL ratio in the present study. In addition to ascorbic acid and flavonoids, LE also contained polyphenols. Whereas polyphenols and flavonoids scavenge hydroxyl and superoxide anions [39], ascorbic acid and flavonoids were shown to synergistically decrease lipid peroxidation and improve lipid profile [38]. In this context, it is worthy to mention that the LE has been shown to possess antioxidant activity in vitro [40], and glabridin, one of the major components of the root, is reported to be a potent antioxidant that prevents LDL oxidation [41, 42].

Our results concerning the effect of antibiotics toward lowering the serum concentrations of total cholesterol and LDL cholesterol were in general disagreement with those of Ashayerizadeh et al. [24], Sarica et al. [43], and Ciftci et al. [44]. Ashayerizadeh et al. [24] reported unchanged serum LDL and HDL cholesterol and higher serum total cholesterol concentrations in broilers fed diets containing $650 \mathrm{mg} / \mathrm{kg}$ of flavomycin, whereas Sarica et al. [43] reported no differences in serum total cholesterol concentration when broilers were received diets containing $1 \mathrm{~g} / \mathrm{kg}$ of flavomycin. Likewise, Ciftci et al. [44] observed no change in serum total cholesterol concentration as a result of feeding a diet containing $10 \mathrm{mg} / \mathrm{kg}$ of avilamycin. The reasons for these discrepancies are unclear; however, the effectiveness of an antimicrobial agent can be influenced by several factors, as discussed above.

\section{Conclusion}

Overall, LE supplementation through drinking improved carcass traits and blood biochemical parameters in broiler chickens. However, because no significant difference was observed on growth performance among the broilers given the control, antibiotic, or the LE levels, further research is needed to confirm the present results and to test the efficacy of LE as an alternative to in-feed antibiotic growth promoters.

\section{Compliance with ethical standards}

\section{Acknowledgments}

This work was funded by Razi University. The authors thank the Department of Animal Science, Agriculture and Natural Resources Center of Kermanshah Province for providing research facilities.

\section{Disclosure of conflict of interest}

The authors have declared that no conflict of interest exists. 


\section{Statement of ethical approval}

All experimental procedures used in the present study adhered to the guidelines of and were approved by the Animal Ethics Committee of Razi University.

\section{References}

[1] Da Costa PM, Bica A, Vaz-Pires P and Bernardo F. (2010). Changes in antimicrobial resistance among faecal enterococci isolated from growing broilers prophylactically medicated with three commercial antimicrobials. Preventive Veterinary Medicine, 93(1), 71-76.

[2] Mukhopadhyay M and Panja P. (2008). A novel process for extraction of natural sweetener from licorice (Glycyrrhiza glabra) roots. Separation and Purification Technology, 63(3), 539-545.

[3] Shalaby MA, Ibrahim HS, Mahmoud EM and Mahmoud AF. (2004). Some effects of Glycyrrhiza glabra (liquorice) roots extract on male rats. Egyptian Journal of Natural Toxins, 1, 83-94.

[4] Doeker BM and Andler W. (1998). Liquorice, growth retardation and Addison's disease. Hormone Research in Paediatrics, 52(5), 253-255.

[5] Suchitra G and Shakunthala V. (2014). Effect of glycyrrhiza glabra root extract on behaviour and fitness of drosophila melanogaster and vestigial wing mutant. International Journal of Current Microbiology and Applied Sciences, 3(7), 1047-1054.

[6] Račková L, Jančinová V, Petríková M, Drábiková K, Nosál’ R, Štefek M, Koštélová D, Prónayová N and Kováčová M. (2007). Mechanism of anti-inflammatory action of liquorice extract and glycyrrhizin. Natural Product Research, 21(14), 1234-1241.

[7] Alkofahi A and Atta AH. (1999). Pharmacological screening of the anti-ulcerogenic effects of some Jordanian medicinal plants in rats. Journal of Ethnopharmacology, 67(3), 341-145.

[8] Al-Qarawi AA, Abdel-Rahman HA and El-Mougy SA. (2001). Hepatoprotective activity of licorice in rat liver injury models. Journal of Herbs, Spices \& Medicinal Plants, 8(1), 7-14.

[9] Tominaga Y, Mae T, Kitano M, Sakamoto Y, Ikematsu H and Nakagawa K. (2006). Licorice flavonoid oil effects body weight loss by reduction of body fat mass in overweight subject. Journal of Health Science, 52(6), 672-683.

[10] Aoki F, Honda S, Kishida H, Kitano M, Arai N, Tanaka H, Yokato S and Nakagawa K. (2007). Suppression by licorice flavonoids of abdominal fat accumulation and body weight gain in high-fat diet-induced obese C57BL/6J mice. Bioscience, Biotechnology, and Biochemistry, 71(1), 206-214.

[11] Armanini D, Palo CB, Mattarello MJ, Spinella P, Zaccaria M, Ermolao A, Palermo M, Fiore C, Sartorato P, FranciniPesenti $\mathrm{F}$ and Karbowiak I. (2003). Effect of licorice on the reduction of body fat mass in healthy subjects. Journal of endocrinological investigation, 26(7), 646-650.

[12] Nakagawa K, Kishida H, Arai N, Nishiyama T and Mae T. (2004). Licorice flavonoids suppress abdominal fat accumulation and increase in blood glucose level in obese diabetic KK-A(y) mice. Biological and Pharmaceutical Bulletin, 27(11), 1775-1778.

[13] SAS Institute. (2003). SAS User's Guide. Version 9.1 reviews. SAS Institute Inc, Cary, NC.

[14] Sedghi M, Golian A, Kermanshahi H and Ahmadi H. (2010). Effect of dietary supplementation of licorice extract and a prebiotic on performance and blood metabolites of broilers. South African Journal of Animal Science, 40(4), 371-380.

[15] Pooryousef Myandoab M and Hosseini Mansoub N. (2012). Comparative effect of liquorice root extract medicinal plants and probiotic in diets on performance, carcass traits and serum composition of Japanese quails. Global Veterinaria, 8(1), 39-42.

[16] Al-Daraji HJ. (2012). The use of liquorice, probiotic, potassium chloride and sodium bicarbonate to counteract the detrimental effects of heat stress on performance of broilers. Global Advanced Research Journal of Agricultural Science, 1(6), 127-135.

[17] Sudarman A and Kaniadewi R (2012). Performance of broiler chickens offered drinking water contained water extracted beluntas (Pluchea indica L.) leaf and sugar cane. Media Peternakan - Journal of Animal Science and Technology, 35(2), 117-122. 
[18] Salman KAA and Ibrahim DK. (2012). Test the activity of supplementation clove (Eugenia caryophyllus) powder, oil and aqueous extract to diet and drinking water on performance of broiler chickens exposed to heat stress. International Journal of Poultry Science, 11(10), 635-640.

[19] Habibian M, Ghazi S and Moeini MM. (2016). Effects of dietary selenium and vitamin E on growth performance, meat yield, and selenium content and lipid oxidation of breast meat of broilers reared under heat stress. Biological Trace Element Research, 169(1), 142-152.

[20] Eseceli H, Demir E, Degirmeneioglu N and Bilgic M. (2010). The effects of bio-Mos® mannan oligosaccharide and antibiotic growth promoter performance of broilers. Journal of Animal and Veterinary Advances, 9(2), 392-295.

[21] Sarker SK, Park SR, Kim GM and Yang CJ. (2010). Hamcho (Salicornia herbacea) with probiotics as alternative to antibiotic for broiler production. Journal of Medicinal Plants Research, 4(5), 415-420.

[22] Lee DN, Lyu SR, Wang RC, Weng CF, and Chen BJ. (2011). Exhibit differential functions of various antibiotic growth promoters in broiler growth, immune response and gastrointestinal physiology. International Journal of Poultry Science, 10(3), 216-220.

[23] Miles RD, Butcher GD, Henry PR and Littell RC. (2006). Effect of antibiotic growth promoters on broiler performance, intestinal growth parameters, and quantitative morphology. Poultry Science, 85(3), 476-485.

[24] Ashayerizadeh A, Dabiri N, Ashayerizadeh O, Mirzadeh KH, Roshanfekr H and Mamooee M. (2009). Effect of dietary antibiotic, probiotic and prebiotic as growth promoters, on growth performance, carcass characteristics and hematological indices of broiler chickens. Pakistan Journal of Biological Sciences, 12(1), 52-57.

[25] Hassan HMA, Mohamed MA, Youssef AW, and Hassan ER. (2010). Effect of using organic acids to substitute antibiotic growth promoters on performance and intestinal microflora of broilers. Asian-Australasian Journal of Animal Sciences, 23(10), 1348-1353.

[26] Wolfenden RE, Pumford NR, Morgan MJ, Shivaramaiah S, Wolfenden AD, Pixley CM, Green J, Tellez G and Hargis BM. (2011). Evaluation of selected direct-fed microbial candidates on live performance and Salmonella reduction in commercial turkey brooding houses. Poultry Science, 90(11), 2627-2631.

[27] Nakai M, Fukui Y, Asami S, Toyoda-Ono Y, Iwashita T, Shibata H, Mitsunaga T, Hashimoto F and Kiso Y. (2005). Inhibitory effects of oolong tea polyphenols on pancreatic lipase in vitro. Journal of Agricultural and Food Chemistry, 53(11), 4593-4598.

[28] Van Gaal LF, Rissanen AM, Scheen AJ, Ziegler 0 and Rossner S. (2005). Effects of the cannabinoid-1 receptor blocker rimonabant on weight reduction and cardiovascular risk factors in overweight patients: 1-year experience from the RIO-Europe study. The Lancet, 365(9468), 1389-1397.

[29] Murase T, Nagasawa A, Hase T, Tokimitsu I, Shimasaki H and Itakura H. (2001). Dietary tea catechins reduce development of obesity accompanied with gene expression of lipid-metabolizing enzymes in mice. Journal of Oleo Science, 50(9), 711-715.

[30] Moharrery A. (2006). Comparison of performance and digestibility characteristics of broilers fed diets containing treated hulled barley or hulless barley. Czech Journal of Animal Science, 51(3), 122-131.

[31] Kamisoyama H, Honda K, Tominaga Y, Yokota S and Hasegawa S. (2008). Investigation of the anti-obesity action of licorice flavonoid oil in diet-induced obese rats. Bioscience, Biotechnology, and Biochemistry, 72(12), 32253231.

[32] Al-Daraji HJ. (2012). Influence of drinking water supplementation with licorice extract on certain blood traits of broiler chickens during heat stress. Report and Opinion, 4(9), 56-60.

[33] Visavadiya NP and Narasimhacharya AVRL. (2006). Hypocholesterolaemic and antioxidant effects of Glycyrrhiza glabra (Linn) in rats. Molecular Nutrition \& Food Research, 50(11), 1080-1086.

[34] Ostlund RE. (2004). Phytosterols and cholesterol metabolism. Current Opinion in Lipidology, 15(1), 37-41.

[35] Harwood HJ, Chandler CE, Pellarin LD, Bangerter FW, Wilkins RW, Long CA, Cosgrove PG, Malinow MR, Marzetta CA and Pettini JL. (1993). Pharmacologic consequences of cholesterol absorption inhibition: alteration in cholesterol metabolism and reduction in plasma cholesterol concentration induced by the synthetic saponin beta-tigogenin cellobioside (CP-88818; tiqueside). The Journal of Lipid Research, 34(3), 377-395.

[36] Venkatesan N, Devaraj SN and Devaraj H. (2003). Increased binding of LDL and VLDL to apo B, E receptors of hepatic plasma membrane of rats treated with Fibernat. European Journal of Nutrition, 42(5), 262-271. 
[37] Gursu MF, Onderci M, Gulcu F and Sahin K. (2004). Effects of vitamin C and folic acid supplementation on serum paraoxonase activity and metabolites induced by heat stress in vivo. Nutrition Research, 24(2), 157-164.

[38] Vinson JA, Hu SJ, Jung S and Stanski AM. (1998). A citrus extract plus ascorbic acid decreases lipids, lipid peroxides, lipoprotein oxidative susceptibility, and atherosclerosis in hypercholesterolemic hamsters. Journal of Agricultural and Food Chemistry, 46(4), 1453-149.

[39] Rice-Evans CA, Miller NJ, Bolwell PG, Bramley PM and Pridham JB. (1995). The relative antioxidant activities of plant-derived polyphenolic flavonoids. Free Radical Research, 22(4), 375-383.

[40] Fuhrman B, Volkova N, Kaplan M, Presser D, Attias J, Hayek T and Aviram M. (2002). Antiatherosclerotic effects of licorice extract supplementation on patients: Increased resistance of LDL to atherogenic modifications, reduced plasma lipid levels, and decreased systolic blood pressure. Nutrition, 18(3), 268-273.

[41] Vaya J, Belinky PA and Aviram M. (1997). Antioxidant constituents from licorice roots isolation, structure elucidation and antioxidative capacity toward LDL oxidation. Free Radical Biology \& Medicine, 23(2), 302-313.

[42] Fukai T, Satoh K, Namura T and Sakagami H. (2003). Antinephritis and radical scavenging activity of prenylflavonoids. Fitoterapia, 74(7-8), 720-724.

[43] Sarica S, Ciftci A, Demir E, Kilinc K and Yildirim Y. (2005). Use of an antibiotic growth promoter and two herbal natural feed additives with and without exogenous enzymes in wheat based broiler diets. South African Journal of Animal Science, 35(1), 61-72.

[44] Ciftci M, Simsek UG, Yuce A, Yilmaz 0 and Dalkilic B. (2010). Effects of dietary antibiotic and cinnamon oil supplementation on antioxidant enzyme activities, cholesterol levels and fatty acid compositions of serum and meat in broiler chickens. Acta Veterinaria Brno, 79(1), 33-40.

\section{How to cite this article}

Moradi N, Ghazi S and Habibian M. (2017). Drinking water supplementation of licorice (Glycyrrhiza glabra L. root) extract as an alternative to in-feed antibiotic growth promoter in broiler chickens.. GSC Biological and Pharmaceutical Sciences, 1(3), 20-28. 